\title{
Resistivity attributes of foundation beds in a sedimentary terrain: Implications on geo-engineering soil conditions
}

\author{
Oyedele, K.F and Ekpoette, K.U \\ Department of Geosciences, University of Lagos, Lagos, Nigeria.
}

\begin{abstract}
Geo-electrical resistivity method was employed to characterize the geo-materials at Isheri, Lagos, Nigeria, for engineering foundation purposes. The methods involved vertical electrical sounding (VES) using Schlumberger array and constant separation traversing (CST) using dipole-dipole array. The results showed the subsurface to be made up of topsoil (clay/peat), clay, sandy clay and sand layers. The topsoil has resistivity values that vary from 16 to $92 \Omega \mathrm{m}$, the clay layer has resistivity values that range from 2 to $21 \Omega \mathrm{m}$, the sandy clay has resistivity values that vary from 34 to $39 \Omega \mathrm{m}$ while the sandy layer has resistivity values that vary from 100 to $724 \Omega \mathrm{m}$. The clay layer has depth values that range between 0.7 to $2.2 \mathrm{~m}$, sandy clay has depth values that vary from 5.5 to $23.6 \mathrm{~m}$ while the sandy layer has depth values that vary from 7.3 to $35.7 \mathrm{~m}$. Based on of the resistivity contrasts coupled with borehole data, shallow foundation may not be feasible in the surveyed area owing to the presence of geological materials with low shear strength and a probable high volume of compressibility upon load application near the surface.
\end{abstract}

Keywords: Geo-electrical, resistivity, pseudo-section, Schlumberger array.

\section{INTRODUCTION}

The properties of soil and rock are the results of the natural processes that have formed them, and natural or man-made events following their formation. The replacement of inferior foundation materials often is impractical and uneconomical. The large volume of soil and rock needed for construction, as a rule, makes it prohibitive to manufacture and transport preengineered materials. The geotechnical expert in designing and constructing facilities is faced with the challenges of using the foundation and construction materials available on or near the project site. Therefore, the designing and building of such structures requires a thorough understanding of properties of available soils and rocks that will constitute the foundation and other components of the structures. The proper execution of this role requires a thorough understanding of the concepts and practice of subsurface investigation techniques and principles, design procedures, construction methods and planned facility utilization.

Generally, there are two types of subsurface investigation that new construction may require; the first being a conceptual subsurface investigation, or route selection study. It generally does not require a detailed subsurface investigation and is normally limited to general observations such as the depth to rock or competent soils, presence of sinkholes and/or solution cavities, organic deposits in low lying swampy areas, and/or evidence of old fill, debris, or contamination. The second and more common type of subsurface investigation is the detailed investigation to be performed for the purpose of detailed site characterization to be used for design. The design investigation typically includes a number of geotechnical and geophysical tests sufficient for defining the general stratigraphy, soil and rock characteristics, groundwater conditions, and other existing features of importance to foundation design (Mayne et. al. 2001, Idornigie, et al 2006).

Several geophysical methods are routinely used to image the subsurface of the earth in support of subsoil investigations. Commonly employed geophysical methods include seismic tomography, ground penetrating radar, electrical resistivity, electromagnetic and gravity methods (Pugin and Largon, 2002, Susan, 2006). However, in terms of spatial resolution, cost effectiveness and target definition, ground penetrating radar and electrical resistivity methods ranked first and second respectively (Neil and Ahmed, 2006). In view of this, electrical resistivity method was used to investigate the subsurface stratigrahic relationships or variation of subsurface materials in Isheri area of Lagos, Nigerian, as an aid to construction engineer. 


\section{Geology of the study area:}

Isheri lies within the Dahomey sedimentary basin that cuts into southwestern Nigeria. The Dahomey is an arcuate coastal basin, the onshore parts of which underlie the coastal plains of southwest Nigeria, Benin, and Togo. It is made up of coastal plain sands, clays and sandstone (Jones and Hockey 1964) this basin extends from Accra in Ghana through to the republic of Togo to the western flanks of Niger delta in the east (Fig.1).
The basin is bounded on the west by fault and other tectonic structures associated with landwards extension of romanche fracture zone (Adegoke et al 1981), its eastern limit is similarly marked by the Benin hinge line. It is a major flat structure marking the western limit of Niger delta basin (Adegoke and Omatsola, 1980). A faulted basement high, the Okitipupa basement ridge, separates the Dahomey from the Benue trough until the Late Creataceous subsidence and marine transgression united both basins.

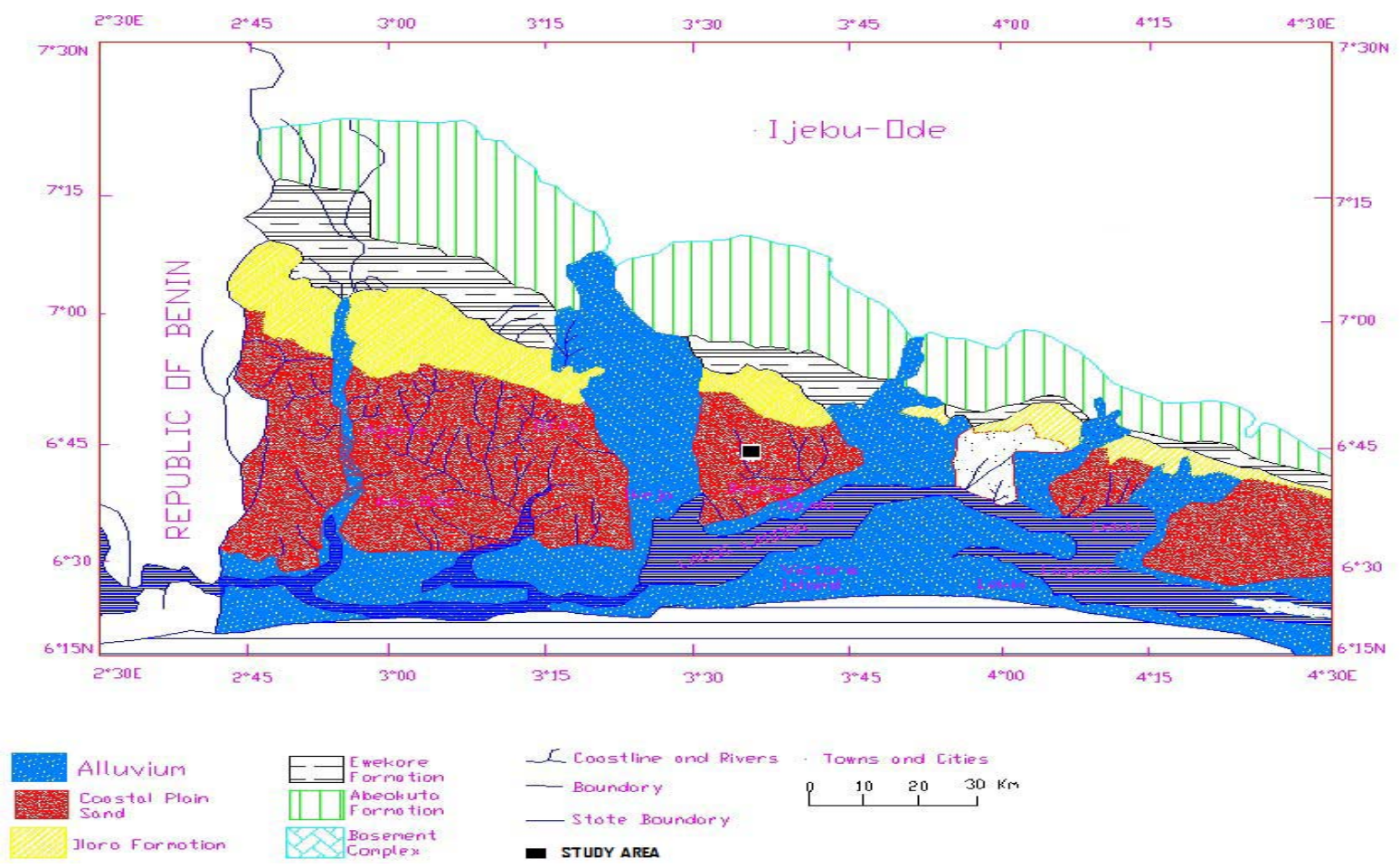

Fig 1: Geologic map of Lagos showing the study area.

Data Acquisition : The data were acquired using ABEM Terrameter model SAS 1000 system. Nine Vertical Electrical Sounding data involving the Schlumberger electrode configuration array and four Constant Separation Traversing data involving Dipole-Dipole array were obtained. A portable battery was used as the power source, while four metal steel rods were utilized as electrodes. Other equipments used include: hammers, four reels of copper wire, Global Positioning System (GPS) and measuring tapes.

The electrodes were arranged using the Schlumberger electrode array and were planted firmly in the ground to ensure good contact. The cables were connected to the electrodes using a cello-tape and to the Terrameter. For the first reading, the potential electrodes and current electrodes were at $0.25 \mathrm{~m}$ and $1 \mathrm{~m}$ respectively from the mid-point. The current electrodes were expanded subsequently symmetrically about the mid point. The potential electrodes were only moved at specified distances so that the Terrameter could measure the corresponding resistivity arising from the current injected into the subsurface using the voltage induced.

Data Processing: To remove unwanted signals and enhance the signal qualities, the VES data was processed using interpretation software for 1-D inversion of apparent resistivity data called WinGlink. The program basically determines a resistivity model 
Am. J. Sci. Ind. Res., 2011, 2(5): 734-739

that approximates the measured data within the limits of data errors and which is in agreement with all prior information. Human errors which normally associated with manual interpretation are reduced to minimum. On the other hand, DIPRO for windows was used to process the 2-D resistivity data. Field data pseudosections and 2-D resistivity structure maps were produced after running inversion of the raw data to filter out the noise. To correlate with resistivity data, one borehole was drilled to aid lithology delineation.

\section{RESULTS AND DISCUSSION}

Geo-electric sections: Several geo-electric sections were produced from the interpreted 1-D resistivity models of the study area. These were further correlated with borehole log for proper lithology identification. The geo-electric sections were developed from the interpreted data in Table 1. In figure 2, it can be seen that a typical representative of the 1-D resistivity model of the study area shows 4layers case, consisting of topsoil (clay/peat), clay, sandy clay and sand. In figure 3, the interpreted resistivity signatures are as follows:

(a) The topsoil has resistivity values that vary from 16 to $92 \Omega \mathrm{m}$,

(b) the clay layer has resistivity values that range from 2 to $21 \Omega m$,

(c) the sandy clay has resistivity values that vary from 34 to $39 \Omega \mathrm{m}$ while

(d) the sandy layer has resistivity values that vary from 100 to $724 \Omega \mathrm{m}$.

On the other hand, the clay layer has depth values that range between 6 to $36 \mathrm{~m}$, sandy clay has depth values that vary from 4 to $8 \mathrm{~m}$ while the sandy layer has depth values that vary from 7 to $17 \mathrm{~m}$. It is apparent here that there is considerable overlap in resistivity values between different rock type, that is why the delineation of subsurface geology is not solely hinged on geophysical data alone. But the method can adequately identify lithologic and hydrogeologic boundaries as seen in figures 3 and 4 . Successful application of any particular method is always site specific and quite often dependent on the experience and judgment of the Geophysicist.

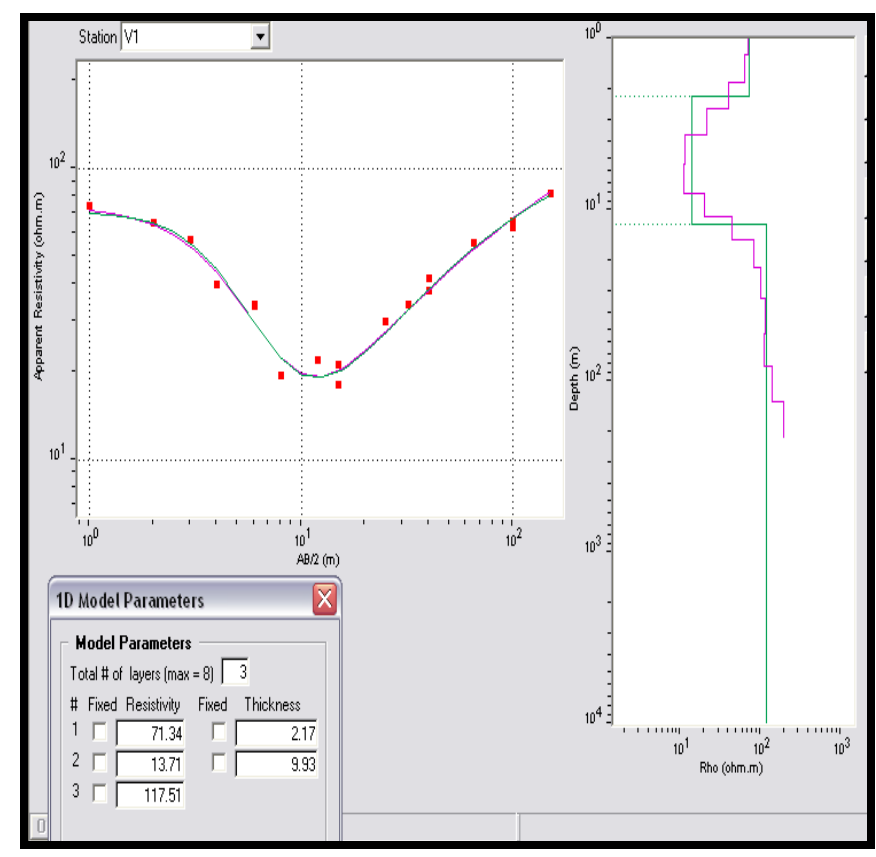

Fig 2a: Representative sample of 1-D resistivity models of the study area.

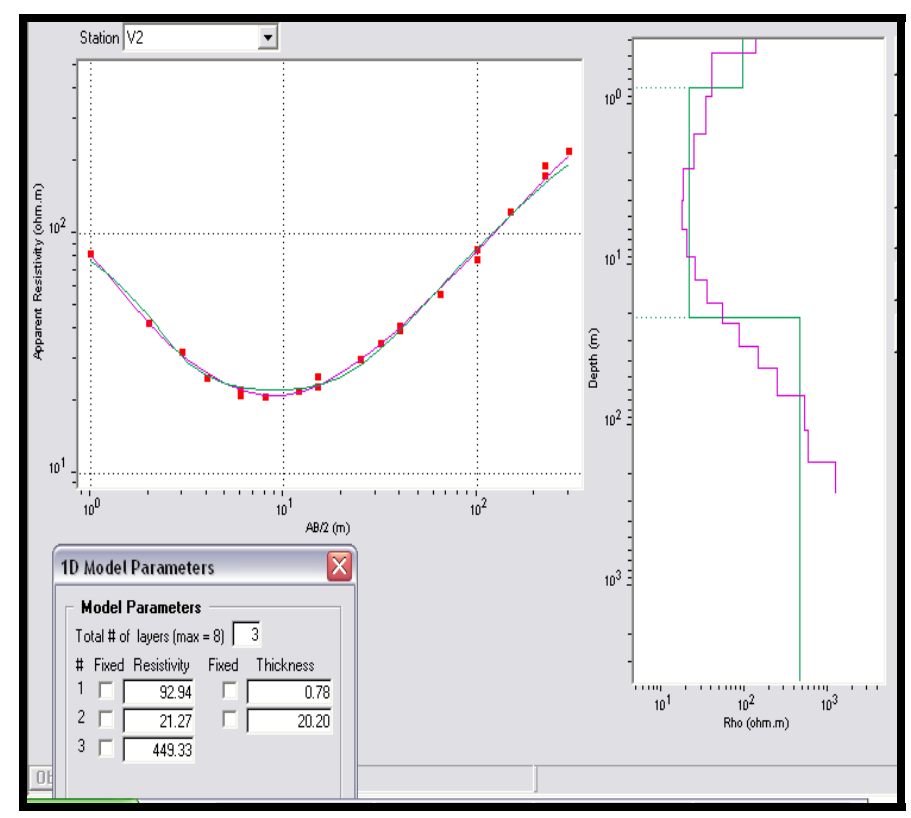

Fig 2b: Representative sample of 1-D resistivity models of the study area. 
Am. J. Sci. Ind. Res., 2011, 2(5): 734-739

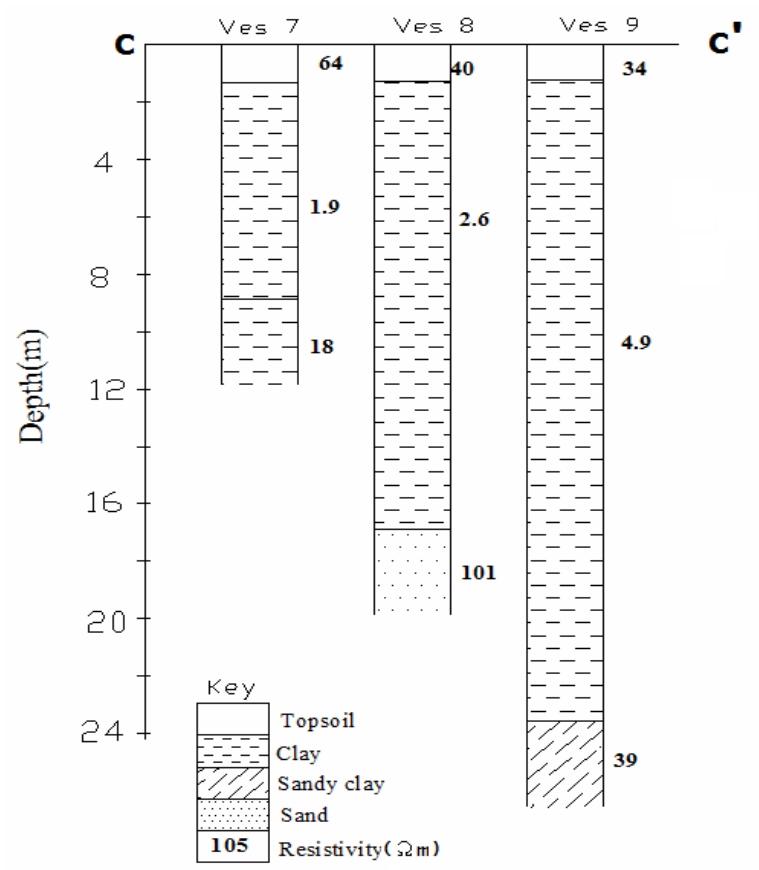

Fig 3: Geo-electric sections beneath VES 7, 8 and 9

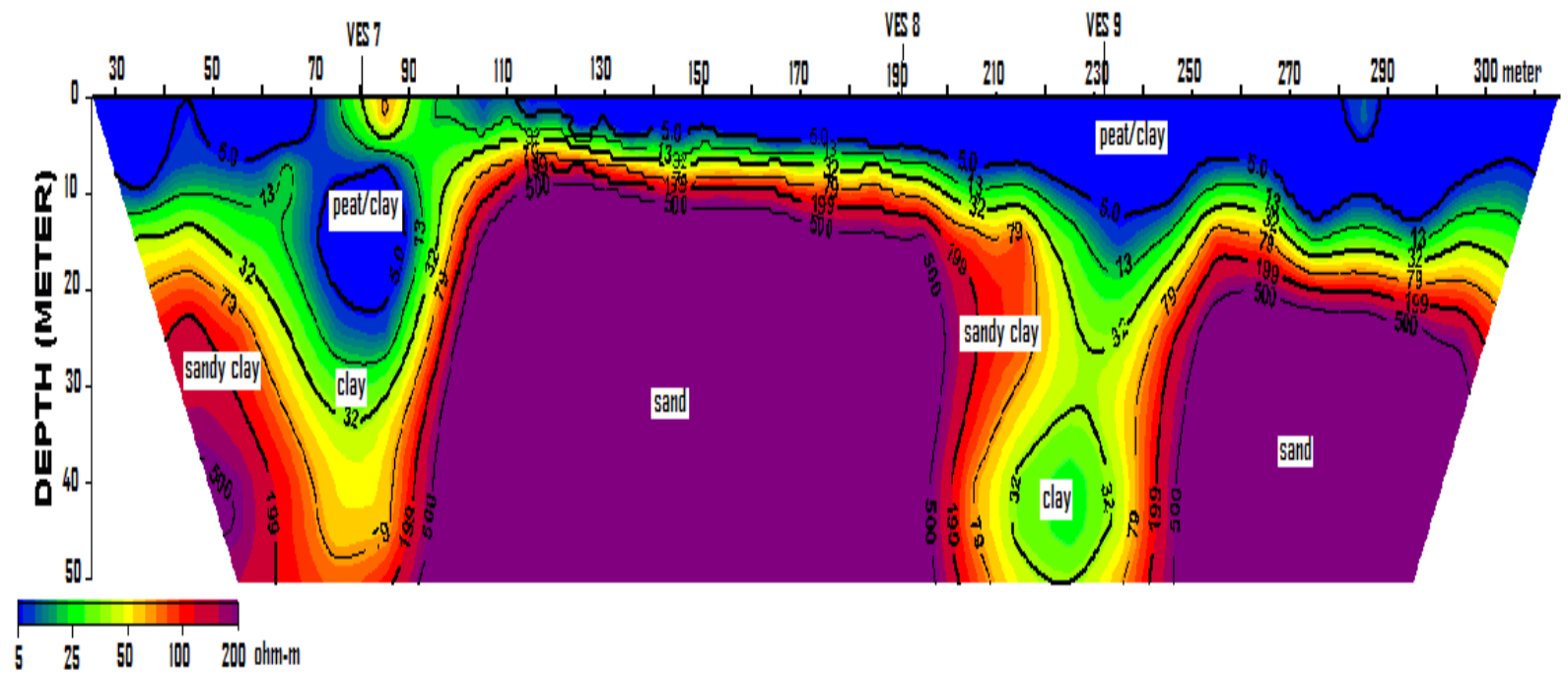

Fig 4: A typical 2-D resistivity pseudo-section of the study area 
2-D Resistivity pseudosection: Figure 4 shows the horizontal variations of resistivity characteristics of the subsurface geology with depth. Also the geologic contact/boundary of each foundation beds as well as their horizontal extent can be seen. From this map it can also be seen that geologic beds are not uniform both vertically and horizontally and also vary asymmetrically in depths. This calls for a caution when geotechnical engineers are deciding on what foundation techniques to be employed in any project as soil is neither uniform nor isotropic as seen in figures 5 .

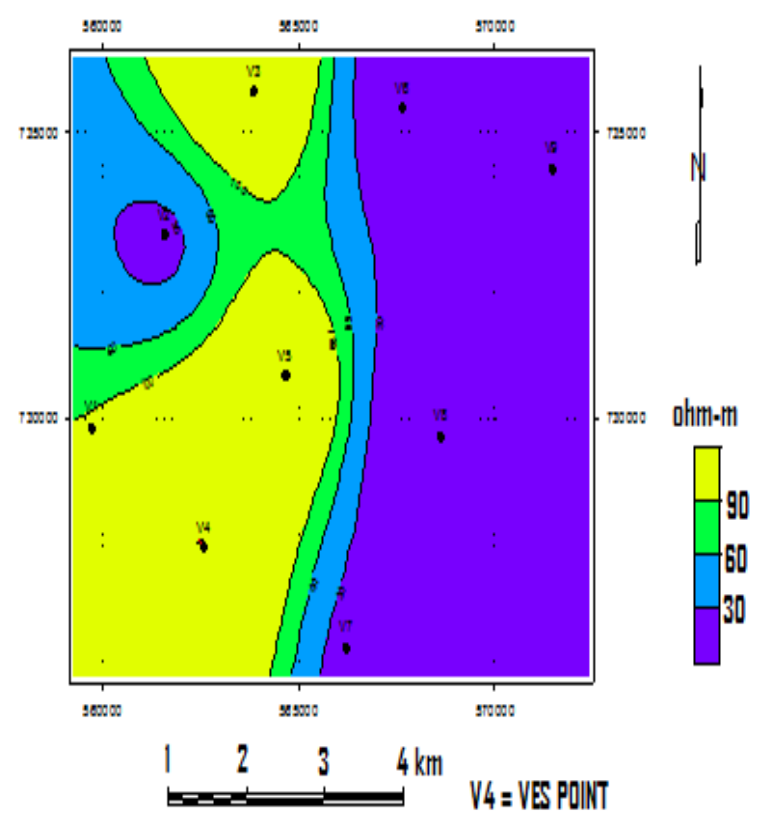

Fig 5a: Subsurface resistivity layered model at $15 \mathrm{~m}$

Iso-resistivity and Depth maps: Maps of resistivity and depth values at selected points were produced to show the subsurface distribution of resistivity values for the delineated geological materials as a way of monitoring the geo-stratigraphic variations along vertical and horizontal extents.

At $15 \mathrm{~m}$ depth, the resistivity values vary between less than 30 to over $725 \Omega \mathrm{m}$, with corresponding lithology of clay and sand. The area is underlain by clay to the east and part of the west side while the central part is mostly underlain by sand (Fig. 5a). At $20 \mathrm{~m}$ depth, the resistivity distribution observed is similar to that obtained at $15 \mathrm{~m}$ depth. Actually, the observed resistivity values vary from 1.20 to $723.88 \Omega \mathrm{m}$. The lithology here comprises of clay, sandy clay and sand (fig $5 b$ ).

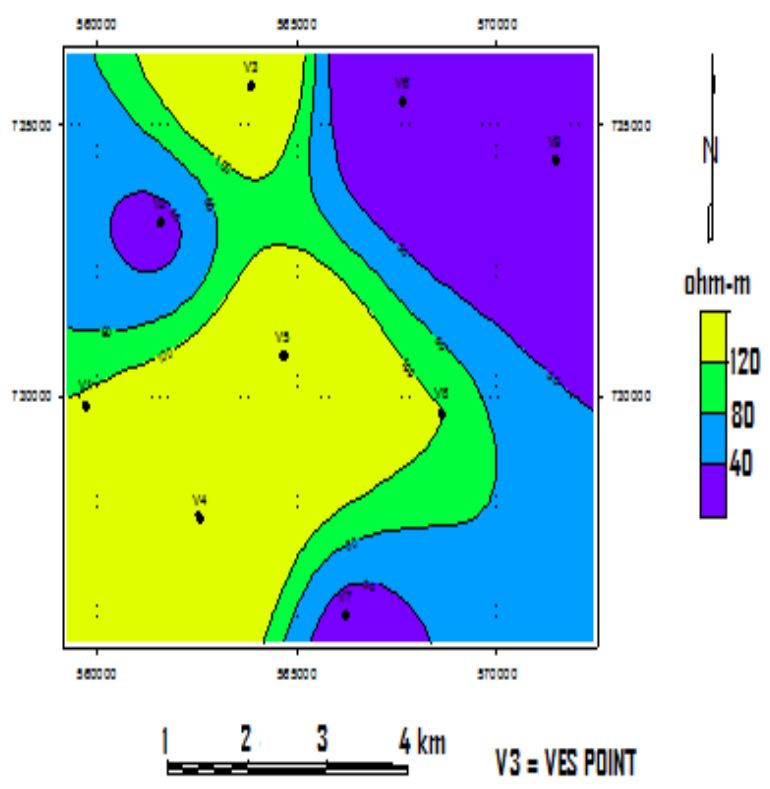

Fig 5b: Subsurface resistivity layered model at $20 \mathrm{~m}$

Implication of the subsurface characteristics on engineering structures: Owing to the presence of clay material near the surface, shallow foundation may not be feasible. The clay layer has depth values that range between 0.7 to $2.2 \mathrm{~m}$ and thickness values which range from 4.0 to $22.3 \mathrm{~m}$. Clay is a highly compressible material with low shear strength and as a result any structure erected on it may undergo differential settlement. Sandy clay has depth values that vary from 5.5 to $23.6 \mathrm{~m}$ and thickness values that vary from 2.5 to over $7.8 \mathrm{~m}$. This mixture of geological material is a good engineering property particularly when the sand aggregates are coarse enough to absorb and bind the clay material together in the presence of water. Depending on the degree of compaction of this material, it can accommodate low to medium engineering structures. The sandy layer has depth values that vary from 7.3 to $35.7 \mathrm{~m}$ but with no thickness values because the current terminated in this layer. To build a giant structure in the study area, it requires piling to the sand layer so as to prevent gradual or sudden collapse of such structure. The presence of water at a shallow depth range of 0.7 to 2.1 is also a serious matter as it makes 
excavation of bad soil much difficult and very expensive.

\section{CONCLUSION}

Contrasts in resisistivity values along side borehole data have been considered adequate in the optimal evaluation of subsurface geo-materials or stratigraphic succession in a sedimentary area of Lagos, Nigeria. The results indicate the subsurface to be made up of clay, sandy clay and sand layers. Shallow foundation may not be feasible in this area because of the presence of clay material that are very close to the surface. Therefore, for engineering structure to be erected on such soil there is need for soil improvement or pilling to the sand layer.

\section{REFERENCES}

Adegoke, O. S., Enu, I. and Ojoh, K. A. (1981). Ostraced Biostratigraphy of the Ewekoro formation. Journal Mining Geo. Sc. Vol. 18, 141 - 153.

Adegoke, O. S. and Omatsola (1980). Tectonic Evolution and Cretaceous Stratigraphy of the Dahomey Basin. Vol. 1 Min-Geol. 130 - 137.

Jones, H.A. and Hockey, R.D. 1964. The geology of part of South Western Nigeria. Geological survey of Nigeria Bulletin No. 31.
Idornigie, A.I. Olorunfemi, M.O and Omitogun, A.A. (2006) Integration of Remotely Sensed and Geophysical Data Sets in Engineering Site Characterization in a Basement Complex Area of Southwestern Nigeria. Journal Applied Sciences Research, 2(9): 541-552.

Pugin, A. J. M. and Larson, T. H. (2002). Geological mapping using geophysics. In Workshop on Geological Models for Groundwater Applications. Denver Co, Gelogical Survey of Canada, Open File 1449, 42-46.

Mayne, W.P., Christopher, B. R. and DeJong, J. (2001) Manual on Subsurface Investigations. National Highway Institute Publication No. FHWA NHI-01-031 Federal Highway Administration Washington, DC. 21 $-22$.

Neil, A. and Ahmed, I. (2006). A generalised protocol for selecting appropriate geophysical techniques. In Workshop on Application of Geophysics. Department of Geology and Geophysics, University of MissouriRolla, Rolla, Missouri, 65401.

Susan, E. P. (2006). The role of geophysics in 3-D mapping. Geological Survey of Canada, ON, KIA 0E8. 